\title{
MAKAM KUNO DI DESA SAKO SEBAGAI SUMBER PEMBELAJARAN SEJARAH
}

\author{
Oleh: Sepri Awiran* \\ *Mahasiswa Program Studi Pendidikan Sejarah FKIP Universitas PGRI Palembang
}

\begin{abstract}
ABSTRAK
Kebudayaan Islam dalam bidang seni, mula-mula masuk ke Indonesia dalam bentuk batu nisan. Di Pasai masih dijumpai batu nisan makam Sultan Malik al-Saleh yang wafat tahun 1292.Rumusan masalah dalam penelitian ini adalah: Nilai sejarah apakah yang ada pada pemakaman kuno di desa Sako yang dapat dijadikan sebagai sumber pembelajaran sejarah? Sedangkan tujuan dari penelitian ini adalah: Untuk mengetahui nilai sejarah apakah yang ada pada pemakaman kuno di desa Sako yang dapat dijadikan sebagai sumber pembelajaran sejarah. Metode yang digunakan dalam penelitian ini adalah metode deskriptif kualitatif dengan teknik pengumpulan data melalui wawancara, observasi, dan studi kepustakaan. Sedangkan teknik analisis data yang digunakan dalam penelitian ini adalah teknik analisis data interaktif melalui pengumpulan data, reduksi data, display data, dan verifikasi data atau penarikan kesimpulan. Berdasarkan hasil analisis data dan pembahasan yang telah dilakukan dalam penelitian ini maka dapat disimpulkan bahwa makam kuno di desa Sako merupakan hasil peninggalan Islam masa Kesultanan Palembang yang dapat dijadikan sebagai sumber pembelajaran sejarah di kelas XI Sekolah Menengah Atas Negeri 1 Tulung Selapan.
\end{abstract}

Kata Kunci: Makam, Desa Sako, Sumber Pembelajaran Sejarah.

\section{A. PENDAHULUAN}

Pembelajaran sejarah dapat memanfaatkan benda, lokasi, situs sebagai sumber, materi dan media dalam pembelajarannya. Salah satu lokasi yang dapat dimanfaatkan dalam pembelajaran sejarah adalah makam kuno di desa Sako. Makam kuno menyimpan data sejarah masa lampau dalam bentuk prasasti/jirat, lokasi dan atribut makam lainnya. Menurut Mazhab Leicester menyatakan bahwa sejarah lokal adalah asal-usul, pertumbuhan, kemunduran, dan kejatuhan dari kelompok masyarakat lokal. Mazhab tersebut memang mengaitkan sejarah lokal dengan kemunduran dan kejatuhan meskipun pada dasarnya sejarah mengalami perubahan, baik mengarah ke kemajuan maupun kemunduran dan kejatuhan (Priyadi, 2012:7).

Salah satunya adalah keberadaan pemakaman kuno di desa Sako suatu hal yang layak untuk dijadikan sebagai sumber pembelajaran sejarah bagi guru, dan siswa. Memanfaatkan sumber-sumber tersebut dapat dilaksanakan dengan metode karya wisata/study tour ke obyek sumber secara langsung, yang bisa dilakukan dalam jam sekolah maupun di luar jam sekolah (KalpataruVolume 1, Nomor 2, Desember 2015:10).

Makam berasal dari kata "maqam" (bahasa Arab) yang berarti tempat berdiri, kemudian arti makam itu berkembang menjadi bangunan kecil dan sebuah kuburan yang keramat. Pengertian makam dalam bahasa Indonesia adalah tempat tinggal atau tempat bersemayam. Secara garis besar kata makam mengandung arti tempat bersemayam orang yang telah meninggal. Secara umum makam biasanya didirikan di sebuah lahan datar, lereng gunung, puncak bukit atau lahan yang sengaja ditinggalkan. Adakalanya makam didirikan di sekitar masjid. Makam dapat juga berupa makam individu atau kompleks (Idris, 2015:1).

Menurut peraturan Islam, maka jika seseorang meninggal (kecuali kalau mati syahid), mayatnya harus dimandikan agar 
bersih (beberapa kali ghusl), kemudian dibungkus dengan kafan, yaitu kain putih yang tidak dijahit. Setelah diberi shalat aljinazah, mayat itu ditanam ditempat yang sudah ditentukan. Di dalam kubur itu mayat diletakkan membujur Utara-Selatan dan miring ke kanan, agar mukanya menghadap ke Barat (kiblat). Untuk bekal menghadapi Munkar dan Nakir, maka sebelum liang kubur itu ditimbun, untuk mayatnya dibacakan do'a at-talqin. Akhirnya sebagai tanda dipancangkanlah nisan di atas timbunan kubur itu. Pada harihari ke-3, ke-7, ke-40, ke-100 dan ke-1000 sesudah meninggalkan seseorang diadakan selamatan, yang dimasukkan sebagai pengantar rohnya ke hadirat Ilahi. Demikian yang biasa berlaku di Indonesia (Soekmono, 1973:82).

Selamatan-selamatan ini adalah unsur dari jaman purba yang hidup terus. Sesuai dengan tradisi maka selamatan pada hari yang ke-1000 adalah upacara terakhir. Sesudah itu bebaslah sudah keluarga yang ditinggalkan itu dari sesuatu kewajiban. Upacara demikian bukanlah yang diharuskan oleh Islam, maka diberbagai daerah terdapatkan perbedaanperbedaan: ada yang mengakhiri upacara itu pada hari yang ke-100 dan ada pula yang menunggu sampai tepat satu malam (Soekmono, 1973:82).

Sesudah upacara terakhir selesai, barulah kuburan itu diabadikan, artinya diperkuat dengan (biasanya) bangunan dari batu. Bangunan ini disebut jirat atau kijing. Nisannnya diganti dengan nisan batu, yang tegak dekat ujung-ujungnya jirat. Di atas jirat ini sering pula, terutama bagi orangorang penting, didirikan sebuah rumah yang disebut (cungkub) atau (kubah) (Soekmono, 1973:83). Tiada bedanya dengan candi, maka makam itu sebagai tempat kediaman yang terakhir dan yang abadi, diusahakan pula untuk menjadi perumahan yang sesuai dengan orang yang dikubur di situ dan dengan alam yang sudah berganti. Terutama pemakaman para raja, seperti istana saja layaknya. Seakan-akan makam itu disamakan saja dengan orangnya, lengkap dengan keluarga serta pembesar-pembesar pengiringnya yang terdekat, bersama-sama tinggal dalam istana. Demikianlah maka pemakaman itu merupakan suatu gugusan cungkub-cungkub dan jirat-jirat, yang dikelompokkan menurut hubungan kekeluargaannya. Gugusan ini dibagi dalam berbagai halaman, yang dipisahkan oleh tembok-tembok tetapi dihubungkan dengan gapura-gapura, sedangkan biasanya sebuah masjid menjadi pelengkapnya (masjid makam) (Mahmud, 2004:88).

Kebudayaan Islam dalam bidang seni, mula-mula masuk ke Indonesia dalam bentuk batu nisan. Di Pasai masih dijumpai batu nisan makam Sultan Malik al-Saleh yang wafat tahun 1292. Batunya terdiri dari pualam putih diukir dengan tulisan arab yang sangat indah berisikan ayat Alquran dan keterangan tentang orang yang dimakamkan serta hari dan tahun wafatnya. Makam-makam yang serupa dijumpai pula di Jawa, seperti makam Maulana Malik Ibrahim di Gersik. Bentuk makam dari abad permulaan masuknya agama Islam menjadi contoh model bagi makam Islam kemudian. Hal ini disebabkan sebelum Islam tidak ada makam. Orang Hindu dan Budha jenazahnya dibakar dan abunya dibuang ke laut, kalau dia seorang kaya abunya disimpan di dalam guci atau kalau dia raja disimpan di dalam candi (Sunanto, 2012:94).

\section{B. METODOLOGI PENELITIAN}

Kata metode berasal dari bahasa Yunani yakni methodos yang berarti cara atau jalan (Hamid, 2011:40). Metode itu sendiri berarti suatu cara, prosedur, atau teknik untuk mencapai sesuatu tujuan secara efektif dan efisien. Metode, karenanya, merupakan salah satu ciri kerja ilmiah (Daliman, 2012:27). Dalam penelitian ini penulis menggunakan penelitian 
kualitatif sebagai cara untuk mengumpulkan data secara akurat. Menurut Kartodirdjo (1982:47) dalam buku Sugeng, metode penelitian kualitatif sering diberlakukan pada ilmu-ilmu kebudayaan (Geisteswissenchaften) yang mencakup humaniora, sejarah, dan ilmu-ilmu sosialyang bertujuan untuk menemukan gejala yang unik atau individual (ideografis) dan bukan mencari hukum-hukum umum (nomotetis) seperti pada ilmu-ilmu alam (Naturwissenschaften) (Usman, 2014:32).

Metode yang digunakan dalam penelitian ini adalah pendekatan deskriptif kualitatif. Berdasarkan rumusan masalah penelitian mendiskripsikan secara merinci dan mendalam mengenai pemakaman kuno di desa Sako sebagai sumber pembelajaran sejarah. Untuk memahami hal tersebut dilakukan penelitian secara mendalam mengenai pemakaman kuno di desa Sako sebagai sumber pembelajaran sejarah.

\section{Jenis dan Sumber Data}

Jenis data yang digunakan dalam penelitian ini adalah data primer dan data skunder. Data primer adalah sumber data yang langsung memberikan data kepada pengumpul data. Dan data skunder merupakan sumber data yang tidak langsung memberikan data kepada pengumpul data (Sugiono, 2010:193).

Data yang digunakan berupa data primer dan sekunder yang menjadi pedoman dalam mendeskripsikan dan menyimpulkan Pemakaman Kuno Di Desa Sako Sebagai Sumber Pembelajaran Sejarah Kelas XI SMA N 1 Tulung Salapan.

\section{Data Primer}

Data primer yang digunakan dalam penelitian ini diperoleh melalui observasi dan wawancara yang dijabarkan sesuai dengan masalah yang ada pada penelitian ini berupa observasi dengan cara analisis morfologi, teknologi, stalistik, kontekstual dan wawancara dengan cara mengajukan pertanyaan pada pakar makam desa Sako yaitu Hakiman.

\section{Data Sekunder}

Data sekunder didapat melalui bukubuku, jurnal, dokumen, foto-foto yang berkaitan dengan masalah dalam penelitian ini. Data tersebut dikumpulkan untuk melengkapi data primer berupa foto-foto selama penelitian berlangsung. Fotofotonya berupa makam 1 bernama Bakarudin Jusup, makam pendamping bernama Hadiburosa dan makam selanjutnya bernama Ariodilah serta foto lokasi penelitian.

\section{HASIL PENELITIAN DAN PEMBAHASAN}

Penelitian ini dilaksanakan di desa Sako, kecamatan Rambutan, kabupaten Banyuasin, provinsi Sumatera Selatan. Untuk mencapai lokasi ini dapat digunakan kendaraan roda dua maupun roda empat yang jaraknya tidak jauh dari pusat kota Palembang, ditempuh 30 menit dari Plaju. Waktu penelitian dilaksanakan selama 2 hari dari tanggal 23 Januari 2016 sampai 24 Januari 2016 (Dokumentasi Penelitian 23-24 Januari 2016).

Keadaan umum situs makam kuno desa Sako dengan keadaan geografis berada di sekitar kebun warga. Ada dua makam yang dikunjungi dalam penelitian dan terpisah pertama di Talang Badak dengan luas wilayah makam lebar $450 \mathrm{~cm}$ dan panjang $925 \mathrm{~cm}$. Luas tanah luar bagian makam lebar $670 \mathrm{~cm}$ dan panjang $1008 \mathrm{~cm}$. Pada makam ini memiliki cungkup dengan jenis bangunan semi permanen cungkup dibangun cukup besar karena di makam ini sering diadakan upacara saat hari besar Islam untuk ukuran pada bagian Utara $450 \mathrm{~cm}$, Selatan 610 $\mathrm{cm}$, Timur dan Barat $925 \mathrm{~cm}$ (Dokumentasi Penelitian 23-24 Januari 2016).

Membuktikan makam ini benar atau tidaknya dari peninggalan masa Islam, itu dilihat dari letak makam apakah 
menghadap ke arah Barat atau kiblat. Makam di desa Sako ini untuk arah makam menghadapnya itu agak berbeda, untuk makam pertama Bakarudin bin Jakub bagian kepala berada di Utara, kaki di Selatan, kiri menghadap makam Barat, dan kanan menghadap makam Timur, makam ini benar arah menghadapnya ke kiblat. Makam pendamping dari makam ini yang bernama Hadiburosa itu menghadapnya ke arah Timur Laut. Dan makam terakhir yang diteliti bernama Ariodillah, makam ini arah menghadapnya ke Timur Laut, jadi makam yang menurut Islam hanya makam bernama Bakaruddin bin Jakub, tapi walaupun begitu masyarakat Desa Sako sudah menganggap makam tersebut sudah masuk Islam dari cerita yang ada sampai sekarang (Dokumentasi Penelitian 23-24 Januari 2016).

Cungkup dilengkapi dengan dinding menggunakan bahan dari batubata dan semen, tinggi bagian dinding pertama 200 $\mathrm{cm}$ sedangkan panjang $433 \mathrm{~cm}$ dan kedua $100 \mathrm{~cm}$ dengan panjang tiga bagian yang berbeda pertama $230 \mathrm{~cm}$, kedua $130 \mathrm{~cm}$ dan ketiga $260 \mathrm{~cm}$ bagian ini cungkup di buat menonjol ke luar untuk menutupi makam yang kedua. Makam ini ada dua untuk ukuran makam utama bernama Bakarudin bin Jakub panjang $207 \mathrm{~cm}$ dan lebar $60 \mathrm{~cm}$ untuk posisi makam sudah di semen ditambah perselin dan dibuat pelataran atau meningkat. Untuk bagian posisi pelataran dari makam ke kiri (Barat) dan kanan (Timur) pelataran yaitu sebelah Barat $110 \mathrm{~cm}$ dan Timur $60 \mathrm{~cm}$, sedangkan untuk pelatarannya lebar $220 \mathrm{~cm}$, tinggi 19 $\mathrm{cm}$, panjang $428 \mathrm{~cm}$ kalau tinggi makam dindingnya di bagian luar sebelah Barat dan Utara $117 \mathrm{~cm}$ dan dalam sebelah Barat $61 \mathrm{~cm}$ dan Timur $90 \mathrm{~cm}$. Untuk bagian makamnya di bagian pelataran panjang $428 \mathrm{~cm}$, lebar $232 \mathrm{~cm}$ dan tinggi $53 \mathrm{~cm}$. Pada makam ini memiliki dua nisan yaitu nisan lama dari kayu dan nisan baru dari batu yang sudah di pola bentuknya dari kepala, leher, tubuh dan kaki, tinggi nisan batu ke tanah $43 \mathrm{~cm}$ panjang makam dari nisan baru ke nisan $338 \mathrm{~cm}$, dan nisan lama panjang makam $280 \mathrm{~cm}$, tinggi nisan kayu $26 \mathrm{~cm}$ dan kemiringan $70 \mathrm{~cm}$ (Dokumentasi Penelitian 23-24 Januari 2016).

Perbedaan ukuran panjang makam ini dari nisan baru dan lama karena nisan kayu itu menunjukkan ukuran lama dan nisan batu itu menunjukkan ukuran baru dari segi penambahan warga setelah melakukan upacara di makam. Pada bagian makam terdapat tiga gundukan tanah, tinggi gundukan besar $22 \mathrm{~cm}$, panjang $46 \mathrm{~cm}$, lebar $47 \mathrm{~cm}$, sedang $8 \mathrm{~cm}$ lebar $24 \mathrm{~cm}$, panjang $22 \mathrm{~cm}$, dan kecil 4 $\mathrm{cm}$, lebar $19 \mathrm{~cm}$, panjang $12 \mathrm{~cm}$ (Dokumentasi Penelitian 23-24 Januari 2016).

Makam kedua bernama Hadiburosa, keterangan dari pengelolah makam (Hakiman) bahwa makam ini adalah seorang pengawal dari makam utama. Panjang ukuran makam $165 \mathrm{~cm}$, lebar 60 $\mathrm{cm}$ dan makam ini sudah ditambah semen dan batubata sehingga bentuknya jirat atau kijing jadi ukurannya panjang $193 \mathrm{~cm}$, lebar $94 \mathrm{~cm}$ dan tinggi $21 \mathrm{~cm}$. Nisan pada makam ini ada tiga semua dari batu yang besar bagian kepala memiliki ukuran panjang $11 \mathrm{~cm}$ dan lebar $10 \mathrm{~cm}$ dan di samping lebar $13 \mathrm{~cm}$, panjang $10 \mathrm{~cm}$, dan tinggi $5,5 \mathrm{~cm}$. Bagian nisan pada kaki panjang $17 \mathrm{~cm}$, lebar $12 \mathrm{~cm}$ dan tinggi $7 \mathrm{~cm}$ (Dokumentasi Penelitian 23-24 Januari 2016).

Penelitian dilanjutkan pada makam selanjutnya yang terletak di awal desa Sako bernama Ariodillah memiliki ukuran panjang makam $506 \mathrm{~cm}$, panjang makam dari dinding ke dinding $710 \mathrm{~cm}$ dan lebar $265 \mathrm{~cm}$ kalau nisan ke dinding bagian kepala 1,10 cm, kaki $77 \mathrm{~cm}$. Makam ini sama memiliki cungkup bangunan semi permanen panjang $1000 \mathrm{~cm}$ dan lebar 483 $\mathrm{cm}$. Cungkup di bangun cukup besar karena di samping makam kita dapat melakukan ziarah ukurannya $260 \mathrm{~cm}$ di 
tambah semen dan perselin, untuk di tengah-tengah di beri batasan agar tanah pada makam rata dengan menggunakan bahan semen dan batubata memiliki panjang $1000 \mathrm{~cm}$ dan lebar $13 \mathrm{~cm}$. Cungkup dilengkapi dengan dinding tingginya $150 \mathrm{~cm}$. Pada makam nisan yang digunakan batu yang sudah di pola pada bagian kepala dan kaki, ukuran pada nisan dari kepala $7 \mathrm{~cm}$, leher $15 \mathrm{~cm}$, tubuh $20 \mathrm{~cm}$ dan kaki $19 \mathrm{~cm}$ (kepala) $15 \mathrm{~cm}$ (kaki), tinggi nisan kepala $56 \mathrm{~cm}$ dan kaki $53 \mathrm{~cm}$ dan untuk kemiringan nisan bagian kepala $35^{\circ}$, kaki $35^{\circ}$, untuk tebalnya $8,5 \mathrm{~cm}$. Makam ini mengahadap Timur Laut di daerah awal desa Sako (Dokumentasi Penelitian 23-24 Januari 2016).

Makam ini memiliki cerita yang melekat di masyarakat setempat sampai sekarang. Awal kisah, setelah kerajaan Majapahit runtuh yang ditaklukan oleh kerajaan Mataram yang terjadi di abad 16. Banyak pembesar-pembesar kerajaan Majapahit tersebut beserta keturunnya mengungsi kepelosok-pelosok tanah air dan salah satu tempat pengungsian pembesar Majapahit tersebut adalah bekas Kerajaan Sriwijaya yang juga sebelumnya merupakan daerah kekuasaan kerajaan Majapahit, pada saat itu kerajaan kesultanan susuhunan Palembang yang pertama (I) yaitu diperintah oleh Sultan Ahmad Najamudin I, Adi Kusumah memerintah pada tahun $1758 \mathrm{M}-1761 \mathrm{M}$ bersamaan tahun $1171 \mathrm{H}-1190 \mathrm{H}$, pengungsi pembesar Majapahit tersebut sudah berada di bumi Palembang (sekarang). Mereka menyusuri sungai Musi diantaranya adalah nenek moyang Sako yaitu Raden Fatahilah (Lazim disebut Raden Ariodilla). Dari sekian lama perjalanan menyusuri sungai Musi akhirnya mereka menghulu kearah Selatan memasuki anak sungai Musi sungai Komering (Sekarang Batang hari Sungai Dua) dan mereka pun memasuki anak sungai Komering yaitu sungai Parung (Sungai pebatasan Marga Parung Priyayi dan OKI), menghilir kearah Timur dan di ujung sungai Parung inilah nenek moyang Sako bertempat tinggal, Raden Fatahilah (7 bersaudara). Disinilah mereka membuka lahan (ladang untuk bercocok tanaman) dan membuat tempat pemukiman serta menjadi tempat mereka mencari hidup, tempat ini sekarang Tanjung Medu atau Leban Kuning (M. Jana, 2010:1-2).

Bertahun-tahun mereka bertempat tinggal, berladangan polanya saat itu yaitu ladang berpindah-pindah, lama kelamaan hampir seluruh dataran tinggi diusahakannya sehingga menjauhi tempat pemukiman asal dan begitulah cara mereka dan akhirnya pindah lagi tempat pemukimannya yaitu sekarang dinamakan Semuruk (Rumah Buruk). Konon ceritanya Raden Ariodila tidak mempunyai keturunan kecuali para pengikutnya. Demikianlah keseharian hidup nenek moyang kita dari hasil ladangnya mereka jual ke Palembang (Masih melalui jalur sungai yaitu berperahu) dan dari hubungan perdagangan inilah nenek moyang Sako banyak menjalin persahabatan dengan orang-orang Kesultanan Palembang, dan ada juga dari anak cucu nenek moyang kita yang menikah dengan keturunan Kesultanan Palembang. Jadi bercampurlah keturunan nenek moyang kita dengan darah Palembang itulah dikatakan keturunan nenek moyang Sako Japal (JawaPalembang). Itulah dari segi bahasa terdapat campuran bahasa antara bahasa Jawa dan bahasa Palembang. Bahasa Jawa diantaranya ending pundit, kulo nuhun, buri (belakang) dan lain-lain. Bahasa Palembang yaitu seperti panggilan kepada anak laki-laki nak Agus. Agama yang dianut nenek moyang Sako pertama yaitu agama Hindu sesuai dengan pada masa itu Kerajaan Majapahit menganut agama Hindu setelah bergaul dengan orang-orang Kesultanan Palembang Darusalam maka berubalah agama yang dianut yaitu Islam (M. Jana, 2010:1-2). 
Para leluhur Desa Sako dahulu membuat desa ini sebelum didiami Diraja (Sesajen) sepanjang 500 meter yaitu untuk menangkal dari serangan binatang buas dan penjahat yang berminat jahat, setelah itu barulah membuat rumah dan tempat peribadatan (Masjid yang sekarang ini berdiri sebelumnya hanya berukuran $8 \mathrm{~m} x$ $8 m$ yang tanahnya merupakan Hibahan dari Khotib Jayo bangunannya terbuat dari kayu dan papan. Pada zaman itu ilmu kanuragan masih menjadi kebanggaan dan untuk mempertahankan diri dari sebuah musuh dan mengatasi keganasan hutan belantara, dan kematian Raden Ariodila pada saat itu juga bukan karena sakit namun terkena ilmu tuju sewaktu beradu ilmu dengan nenek moyangnya desa Sungai Dua. Ceritanya pada saat itu nenek moyang Sako beradu ilmu dengan nenek moyang desa Sungai Dua dan sebelum bertanding nenek moyang kita berpesan kepada pengikutnya "kalau suatu saat saya tercundang (terkena) dan meninggal tolong kalian jangan bersedih, namun kalian siapkan pesta kemenangan dengan Gendang Tetawak diiringi Pencak Silat, dan hiasi aku". Dan pada hari untuk beradu ilmu kanuragan dan singkat cerita nenek moyang kita meninggal. Sesuai dengan pesan yang telah disampaikan maka dibuatkanlah pesta dengan tetabuan Gendang Tetawak diiringi Pecak Silat. Dan ketika telik sandi dari desa Sungai Dua datang mereka merasa kaget bukanlah isak tangis yang mereka dapatkan namun pesta meriah Pencak Silat dengan diiringi Gendang Tetawak, bergegas mereka pulang mengabari kepada junjungannya, kontan merasa kecewa ia merasa ilmunya tidak ada apa-apanya, dan akhirnya ilmunya serta seluruh kitabnya dibuang (Tempat pembuangannya sekarang dikenal dengan nama Batu Ngelaso). Raden Ariodila wafat sekitar abad ke 17 dalam keadaan beragama Islam (M. Jana, 2010:23).
Setelah meninggalnya Raden Ariodila lalu dimakamkan dibelakang dusun Semuruk, itulah makam Ariodila banyak dikenal dengan nama Buyut Semuruk. Kuburan tersebut dengan panjang 7 meter. Tradisi desa Sako berziarah pemakam Puyang Ariodila setiap I Muharam. Sambil membawa sesajian bersedekahan untuk makan bersama. Mengapa dinamakan Sako? ceritanya pada saat itu Kesultanan Palembang Darusalam sedang membangun Masjid Lawang Kidul. Maka Kesultanan Palembang meminta bantuan kepada warga Parung Priyayi untuk menyumbang Sako (tiang) Masjid, maka terdengarlah anak keturunan Ariodila dan mereka sanggup untuk mengambil Sako tersebut, setelah akan diantarkan terdengarlah berita bahwa Sako yang diminta oleh Kesultanan Palembang Darusalam sudah cukup. Dan akhirnya Sako (tiang) yang sudah siap diantarkan dan tetap ditempatnya hingga membusuk. Ditempat pemangkalan apabila berperahu ingin ke Palembang dan tempat itu akhirnya disebut Sako. Dan dari nama itulah yang akhirnya sekarang Desa kita ini dinamakan Desa Sako, aktifitas ladang perpindah-pindah ini sudah menjadi kebiasaan. Lama-kelamaan juga menjauhi tempat pemukiman semula dan akhirnya menempati disekitar seberang jalan Simpang teluk Bunyian bukti yang masih dilihat sampai sekarang yaitu sumur Cangkring dan pemakamannya dikenal sekarang Makam (M. Jana, 2010:4).

\section{Penyebaran Islam di Uluan Abad 18-19 dari Cerita Rakyat}

Ariodillah datang bersama kawanannya ke desa Sako dengan menyusuri anak sungai Musi yaitu sungai Komering beliau dianggap orang tertua di desa Sako atau nenek Buyut desa Sako. Agama yang dianut nenek moyang Sako yaitu agama Hindu sesuai dengan pada masa itu Kerajaan Majapahit menganut agama Hindu setelah bergaul dengan 
orang-orang Kesultanan Palembang Darusalam maka berubalah agama yang dianut yaitu Islam (Catatan Penelitian 23-24 Januari 2016).

Masyarakat desa Sako sudah mulai menjalin hubungan perdagangan dengan orang Kesultanan Palembang dengan menjual hasil ladangnya, nenek moyang Sako juga banyak menjalin persahabatan dengan orang-orang Kesultanan Palembang, dan ada juga dari anak cucu nenek moyang Sako yang menikah dengan keturunan Kesultanan Palembang. Jadi bercampurlah keturunan nenek moyang Sako dengan darah Palembang itulah dikatakan keturunan nenek moyang Sako Japal (Jawa-Palembang). Itulah dari segi bahasa terdapat campuran bahasa antara bahasa Jawa dan bahasa Palembang. Bahasa Jawa diantaranya ending pundit, kulo nuhun, buri (belakang) dan lain-lain. Bahasa Palembang yaitu seperti panggilan kepada anak laki-laki nak Agus. Agama yang dianut nenek moyang Sako pertama yaitu agama Hindu sesuai dengan pada masa itu Kerajaan Majapahit menganut agama Hindu setelah bergaul dengan orang-orang Kesultanan Palembang Darusalam maka berubalah agama yang dianut yaitu Islam (Catatan Penelitian 23-24 Januari 2016).

Dari uraian di atas menjelaskan bagaimana nilai sejarah yang ada pada makam kuno di desa Sako. Pada abad 1819 penyebaran Islam di uluan saat itu sudah dirasakan masyarakat dari hubungan dagang dan pernikahan. Agama yang dianut awalnya Hindu dapat berubah setelah pergaulan yang erat dengan orangorang dari Kesultanan Palembang maka agamapun berubah menjadi Islam (Catatan Penelitian 23-24 Januari 2016).

\section{Tradisi Ziarah}

Menurut cerita dari Hakiman seorang pengurus makam di desa Sako dalam Wawancara tanggal 23 Januari 2016. Mengatakan bahwa, Makam 1 bernama
Bakaruddin bin Jakub. Makam ini merupakan anak dari Suyal. Banyak pengunjung yang datang ke makam ini di hari besar Islam dengan membawa sesajen, berdoa bersama dengan ilmu Tasawuf (Kebatinan) dan dilanjutkan penyembelihan seekor kambing. Pengunjug yang datang banyak dari desa Sako sendiri di hari besar Islam, untuk pengunjung dari luar desa Sako yang datang untuk melakukan ziarah itu sedikit sekali karena niat pengujung bermacammacam. Pengunjung yang datang biasanya hanya berdoa. (Catatan Penelitian 23-24 Januari 2016).

Makam selanjutnya makam Arriodillah, Setelah meninggalnya Raden Ariodila lalu dimakamkan dibelakang dusun Semuruk, itulah makam Ariodila banyak dikenal dengan nama Buyut Semuruk. Kuburan tersebut dengan panjang 7 meter. Tradisi desa Sako berziarah pemakam Puyang Ariodila setiap I Muharam. Sambil membawa sesajian bersedekahan untuk makan bersama. Tradisi ini dilakukan setiap hari besar Islam, masyarakat selalu berzairah dengan membawa sesajen dan berdoa dengan ilmu Tasawuf bersama dengan niat masyarakat menghormati jasa nenek moyang mereka. Untuk pengunjung dari luar desa Sako yang datang untuk melakukan ziarah itu sedikit sekali karena niat pengujung bermacam-macam. Pengunjung yang datang biasanya hanya berdoa, dan pernah di makam ini orang yang berzairah dengan bermalam (Catatan Penelitian 23-24 Januari 2016).

\section{Cerita Rakyat}

Menurut cerita dari Hakiman seorang pengurus makam di desa Sako dalam Wawancara tanggal 23 Januari 2016. Mengatakan bahwa, Makam 1 bernama Bakaruddin bin Jakub. Makam ini merupakan anak dari Suyal. Banyak pengunjung yang datang ke makam ini di hari besar Islam dengan membawa sesajen dan dilanjutkan penyembelihan seekor 
kambing. Pengunjug yang datang banyak dari desa Sako sendiri, di hari Islam ada sedikit orang dari luar desa Sako yang datang untuk melakukan ziarah. Nilai sejarah dari makam ini adalah ilmu Tasawuf. Di samping makam 1 ini ada makam lain yang mendampingi bernama Hadiburosa sebagai pengawal (Catatan Penelitian 23-24 Januari 2016).

Selanjutnya pada makam 2 bernama Ariodillah, Awal kisah, setelah Kerajaan Majapahit runtuh yang ditaklukan oleh Kerajaan Mataram yang terjadi di abad 16. Banyak pembesar-pembesar Kerajaan Majapahit tersebut beserta keturunnya mengungsi kepelosok-pelosok tanah air dan salah satu tempat pengungsian pembesar Majapahit tersebut adalah bekas Kerajaan Sriwijaya yang juga sebelumnya merupakan daerah kekuasaan Kerajaan Majapahit, pada saat itu kerajaan Kesultanan susuhunan Palembang yang pertama (I) yaitu diperintah oleh Sultan Ahmad Najamudin I, Adi Kusumah memerintah pada tahun $1758 \mathrm{M}-1761 \mathrm{M}$ bersamaan tahun $1171 \mathrm{H}-1190 \mathrm{H}$, pengungsi pembesar Majapahit tersebut sudah berada di bumi Palembang (sekarang). Mereka menyusuri sungai Musi diantaranya adalah nenek moyang Sako yaitu Raden Fatahilah (Lazim disebut Raden Ariodilla). Dari sekian lama perjalanan munyusuri sungai Musi akhirnya mereka menghulu kearah Selatan memasuki anak sungai Musi sungai Komering (Sekarang Batang hari Sungai Dua) dan mereka pun memasuki anak sungai Komering yaitu sungai Parung (Sungai pebatasan Marga Parung Priyayi dan OKI), menghilir kearah timur dan diujung sungai Parung inilah nenek moyang Sako bertempat tinggal, Raden Fatahilah (7 bersaudara). Disinilah mereka membuka lahan (ladang untuk bercocok tanaman) dan membuat tempat pemukiman serta menjadi tempat mereka mencari hidup, tempat ini sekarang Tanjung Medu atau Leban Kuning (M. Jana, 2010:1-2).
Bertahun-tahun mereka bertempat tinggal, berladangan polanya saat itu yaitu ladang berpindah-pindah, lama kelamaan hampir seluruh dataran tinggi diusahakannya sehingga menjauhi tempat pemukiman asal dan begitulah cara mereka dan akhirnya pindah lagi tempat pemukimannya yaitu sekarang dinamakan Semuruk (Rumah Buruk). Konon ceritanya Raden Ariodila tidak mempunyai keturunan kecuali para pengikutnya. Demikianlah keseharian hidup nenek moyang kita dari hasil ladangnya mereka jual ke Palembang (Masih melalui jalur sungai yaitu berperahu) dan dari hubungan perdagangan inilah nenek moyang Sako banyak menjalin persahabatan dengan orang-orang Kesultanan Palembang, dan ada juga dari anak cucu nenek moyang kita yang menikah dengan keturunan Kesultanan Palembang (M. Jana, 2010:1-2).

Jadi bercampurlah keturunan nenek koyang kita dengan darah Palembang itulah dikatakan keturunan nenek moyang Sako Japal (Jawa-Palembang). Itulah dari segi bahasa terdapat campuran bahasa antara bahasa Jawa dan bahasa Palembang. Bahasa Jawa diantaranya ending pundit, kulo nuhun, buri (belakang) dan lain-lain. Bahasa Palembang yaitu seperti panggilan kepada anak laki-laki nak Agus. Agama yang dianut nenek moyang Sako pertama yaitu agama Hindu sesuai dengan pada masa itu Kerajaan Majapahit menganut agama Hindu setelah bergaul dengan orang-orang Kesultanan Palembang Darusalam maka berubalah agama yang dianut yaitu Islam (M. Jana, 2010:1-2).

\section{Ragam Hias}

Bentuk makam pertama bernama Bakaruddin bin Jakub hanya di tambah menggunakan semen, batubata, dan perselin. Makam ini ada dua untuk ukuran makam utama bernama Bakarudin bin Jakub panjang $207 \mathrm{~cm}$ dan lebar $60 \mathrm{~cm}$ untuk posisi makam sudah di semen 
ditambah perselin dan di buat pelataran atau meningkat. Untuk bagian posisi pelataran dari makam ke kiri (barat) dan kanan (timur) pelataran yaitu sebelah Barat $110 \mathrm{~cm}$ dan Timur $60 \mathrm{~cm}$, sedangkan untuk pelatarannya lebar $220 \mathrm{~cm}$, tinggi $19 \mathrm{~cm}$, panjang $428 \mathrm{~cm}$ kalau tinggi makam dindingnya di bagian luar sebelah barat dan utara $117 \mathrm{~cm}$ dan dalam sebelah barat 61 $\mathrm{cm}$ dan timur $90 \mathrm{~cm}$. Untuk bagian makamnya dibagian pelataran panjang 428 $\mathrm{cm}$, lebar $232 \mathrm{~cm}$ dan tinggi $53 \mathrm{~cm}$. Pada makam ini memiliki dua nisan yaitu nisan lama dari kayu dan nisan baru dari batu yang sudah di pola bentuknya dari kepala, leher, tubuh dan kaki, tinggi nisan batu ke tanah $43 \mathrm{~cm}$ panjang makam dari nisan baru ke nisan $338 \mathrm{~cm}$, dan nisan lama panjang makam $280 \mathrm{~cm}$, tinggi nisan kayu $26 \mathrm{~cm}$ dan kemiringan $70 \mathrm{~cm}$. Pada makam ini tidak ada ukiran-ukiran atau angka tahun, dan untuk nisannya dari nisan pertama yang digunakan hanya nisan kayu yang dibentuk segitiga, dan nisan yang kedua diganti dengan menggunakan batu yang sudah diukir berundak (Dokumentasi Penelitian 23-24 Januari 2016).

Untuk makam kedua bernama Hadiburosa atau makam pendamping, bentuknya sama seperti makam pertama hanya ditambah dengan menggunakan semen, batubata, dan perselin. Nisannya menggunakan batu. Dibangun cungkup oleh masyarakat dengan bangunan semi permanen. Makam kedua bernama Hadiburosa, keterangan dari pengelolah makam (Hakiman) bahwa makam ini adalah seorang pengawal dari makam utama. Panjang ukuran makam $165 \mathrm{~cm}$, lebar $60 \mathrm{~cm}$ dan makam ini sudah ditambah semen dan batubata sehingga bentuknya jirat atau kijing jadi ukurannya panjang 193 $\mathrm{cm}$, lebar $94 \mathrm{~cm}$ dan tinggi $21 \mathrm{~cm}$. Nisan pada makam ini ada tiga semua dari batu yang besar bagian kepala memiliki ukuran panjang $11 \mathrm{~cm}$ dan lebar $10 \mathrm{~cm}$ dan di samping lebar $13 \mathrm{~cm}$, panjang $10 \mathrm{~cm}$, dan tinggi $5,5 \mathrm{~cm}$. Bagian nisan pada kaki panjang $17 \mathrm{~cm}$, lebar $12 \mathrm{~cm}$ dan tinggi $7 \mathrm{~cm}$ (Dokumentasi Penelitian 23-24 Januari 2016).

Pada makam selanjutnya, bernama Ariodillah. Makam ini ditambah menggunakan semen dan batubata. Nisannya menggunakan nisan dari batu yang sudah di bentuk berundak. Makam ini memiliki panjang 7 meter. Makam ini juga diibangun cungkup dengan bangunan semi permanen. Sewaktu zairah pengunjung dapat berdoa di depan makam karena sudah ditambah porselin untuk pengunjung duduk (Catatan Penelitian 23-24 Januari 2016).

Makam terletak di awal desa Sako bernama Ariodillah memiliki ukuran panjang makam $506 \mathrm{~cm}$, panjang makam dari dinding ke dinding $710 \mathrm{~cm}$ dan lebar 265 $\mathrm{cm}$ kalau nisan ke dinding bagian kepala $1,10 \mathrm{~cm}$, kaki $77 \mathrm{~cm}$. Makam ini sama memiliki cungkup bangunan semi permanen panjang $1000 \mathrm{~cm}$ dan lebar 483 $\mathrm{cm}$. Cungkup dibangun cukup besar karena di samping makam kita dapat melakukan ziarah ukurannya $260 \mathrm{~cm}$ di tambah semen dan porselin, untuk di tengah-tengah diberi batasan agar tanah pada makam rata dengan menggunakan bahan semen dan batubata memiliki panjang $1000 \mathrm{~cm}$ dan lebar $13 \mathrm{~cm}$. Cungkup dilengkapi dengan dinding tingginya $150 \mathrm{~cm}$. Pada makam nisan yang digunakan batu yang sudah di pola pada bagian kepala dan kaki, ukuran pada nisan dari kepala $7 \mathrm{~cm}$, leher $15 \mathrm{~cm}$, tubuh $20 \mathrm{~cm}$ dan kaki $19 \mathrm{~cm}$ (kepala) $15 \mathrm{~cm}$ (kaki), tinggi nisan kepala $56 \mathrm{~cm}$ dan kaki $53 \mathrm{~cm}$ dan untuk kemiringan nisan bagian kepala $35^{\circ}$, kaki $35^{\circ}$, untuk tebalnya $8,5 \mathrm{~cm}$. Makam ini mengahadap timur laut di daerah awal desa Sako (Dokumentasi Penelitian 23-24 Januari 2016).

\section{SIMPULAN}

Berdasarkan hasil penelitian dan pembahasan dapat saya simpulkan sebagai berikut: 
1. Provinsi Sumatera Selatan memiliki kekayaan sejarah dan budaya lokal yang sangat tinggi. Salah satu situs yang dapat dijadikan sebagai sumber pembelajaran sejarah di SMA adalah makam Bakaruddin bin Jakub dan makam Ariodillah kuno di desa Sako.

2. Makam kuno di desa Sako berasal dari abad 18-19.

\section{DAFTAR PUSATAKA}

Daliman, A. 2012. Manusia dan Sejarah. Yogyakarta: Ombak.

Hamid, ABD Rahman dan Muhammad Saleh Madjid. 2011. Pengantar IImu Sejarah. Yogyakarta: Ombak.

Idris, Muhamad, dkk. 2015. Modul Praktek Mata Kuliah Sejarah Indonesia 3. Palembang: Program Studi Pendidikan Sejarah Jurusan Pendidikan IImu Pengetahuan Sosial Fakultas Keguruan dan IImu Pendidikan Universitas PGRI Palembang.

M. Jana, Sugiharto. 2010. Sejarah Desa dan Masa Pemerintahan Desa Sako "Jilid I". Palembang.

Mahmud, Kiagus Imran. 2004. Sejarah Palembang. Palembang: Anggrek Palembang.

Priyadi, Sugeng. 2012. Sejarah Lokal "Konsep, Metode Dan Tantangannya". Yogyakarta: Ombak.

Soekmono, R. 1973. Pengantar Sejarah Kebudayaan Indonesia 3. Yogyakarta: Kanisius.

Sunanto, Musyrifah. 2012. Sejarah Peradaban Islam Indonesia. Jakarta: PT Rajagrafindo Persada.

Usman, Husaini dan Purnomo Setiady Akbar. 2014. Metodologi Penelitian Sosial "Edisi ke-2". Jakarta: Bumi Aksara.

\section{A. Sumber Jurnal}

Kalpataru, Volume 1 Nomor 1. Juli 2015. Palembang: Universitas Persatuan
Guru Republik Indonesia Palembang. ISSN: 2460-6383.

\section{B. Sumber Non Buku}

Wawancara dengan Pak Hakiman (Pengelola Makam) pada hari Sabtu dan Minggu tanggal 23-24 Januari 2016. 